\title{
The Potential Role of Exercise Training and Mechanical Loading on Bone-Associated Skeletal Nerves
}

\author{
Stefano Negri ${ }^{1}$, T. Jake Samuel ${ }^{2}$, Seungyong Lee $^{3}$ \\ 'Department of Orthopedics and Trauma Surgery, Department of Surgery, Dentistry, Pediatrics and Gynecology of the University of Verona, \\ Verona, Italy \\ ${ }^{2}$ Division of Cardiology, Department of Medicine, Johns Hopkins University School of Medicine, Baltimore, MD; \\ ${ }^{3}$ Department of Physiology, College of Graduate Studies, Midwestern University Arizona College of Osteopathic Medicine, Glendale, AZ, USA
}

\author{
Corresponding author \\ Seungyong Lee \\ Department of Physiology, College of \\ Graduate Studies, Midwestern University \\ Arizona College of Osteopathic Medicine, \\ 19555 N. 59th Ave., Glendale, AZ 85308, USA \\ Tel: +1-623-572-3721 \\ Fax: +1-623-572-3673 \\ E-mail: slee@midwestern.edu
}

Received: October 20, 2021

Revised: November 3, 2021

Accepted: November 7, 2021

This study has been presented at the 9th Seoul Symposium on Bone Health (SSBH) and the 33rd Spring Scientific Congress of the Korean Society for Bone and Mineral Research (KSBMR) (3 Jun. 2021 -5 Jun. 2021).

Copyright (C) 2021 The Korean Society for Bone and Mineral Research

This is an Open Access article distributed under the terms of the Creative Commons Attribution Non-Commercial License (https://creativecommons.org/licenses/by-nc/4.0/) which permits unrestricted non-commercial use, distribution, and reproduction in any medium, provided the original work is properly cited.

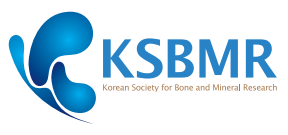

The spatial distribution, innervation, and functional role of the bone-associated skeletal nerves have been previously reported in detail. However, studies examining exercise-induced associations between skeletal nerves and bone metabolism are limited. This review introduces a potential relationship between exercise and the skeletal nerves and discusses how it can contribute to exercise-induced bone anabolism. First, the background and current understanding of nerve fiber types and their functions in the skeleton are provided. Next, the influence of exercise and mechanical loading on the skeletal nervous system is elaborated. Effective synthesis of recent studies could serve as an established baseline for the novel discovery of the effects of exercise on skeletal nerve density and bone anabolic activity in the future. Therefore, this review overviews the existing evidence for the neural control of bone metabolism and the potential positive effects of exercise on the peripheral skeletal nervous system. The influence of exercise training models on the relationships of sensory nerve signals with osteoblast-mediated bone formation and the increased bone volume provides the first insight on the potential importance of exercise training in stimulating positive adaptations in the skeletal nerve-bone interaction and its downstream effect on bone metabolism, thereby highlighting its therapeutic potential in a variety of clinical populations.

Key Words: Adaptation, physiological · Bone and bones · Exercise · Nervous system

\section{INTRODUCTION}

The bone is a living organ system that plays a vital role in the life of all mammalian species. The skeletal system helps form body structure which allows for kinetic movement and protects other vulnerable vital internal organs, such as the brain, by shielding them adamantly. In addition, the skeleton is a major regulator of calcium metabolism and mineral depository. Bone remodeling involves numerous dynamic processes that help maintain bone strength and mineral-calcium homeostasis, regulated by numerous bone-specific cells including bone-resorbing osteoclasts, bone-forming osteoblasts, osteocytes, and bone lining cells.[1,2]

The molecular processes governing the bone formation and degradation are 
highly dynamic and adaptable, leading to continuous bone tissue remodeling in response to physiological stress, such as the dynamic load experienced by the long bones during exercise. Indeed, weight-bearing exercise triggers multiple physiological mechanisms leading to the generation of muscle and mechanical loading reaction forces.[3] Generally, exercise is known to increase the mechanical signals on the bone, such as dynamic tension and compression, which further promote osteogenic differentiation of mesenchymal stem cells [4] and activates osteoblasts.[5] Therefore, the mechanical stress induced by exercise is an exceptionally powerful stimulus to bone cells.

While the effects of physical activity and exercise training on bone structure and bone metabolism are relatively well-known by now, their effects on skeletal nerve function and adaptation remained equivocal until recently. Moreover, similar to how exercise training has been associated with neurological and cognitive benefits in brain related diseases,[6-9] there is pre-clinical evidence to suggest that chronic exercise training also elicits increased periosteal nerve fibers in peripheral bone tissue.[10] The purpose of the current review is to describe the cross-talk between skeletal nerves and their impact on bone function and metabolism, summarize recent evidence highlighting the effects of exercise on the skeletal nervous system, before finally highlighting gaps in the literature that might further advance current understanding of the potential therapeutic role of exercise training in a variety of bone related diseases.

\section{TYPES AND FUNCTION OF SKELETAL NERVES}

\section{Different types of nerves in bone}

The skeleton is a large living tissue and is richly innervated by both sensory and sympathetic nerve fibers, in conjunction with a dense bone vascular system (Fig. 1),[11-13] and extends its effects to bone cells, specifically osteoblasts and osteoclasts, which implies that these nerve fibers and the dynamic neural transmission they facilitate may play a regulatory role in local bone metabolism. Specifically in the skeleton, most of the neurotrophic receptors for myelinated and unmyelinated sensory nerves are tropomyosin receptor kinase A (TrkA).[14] As the high-affinity receptor for a nerve growth factor (NGF), the NGF-TrkA signaling

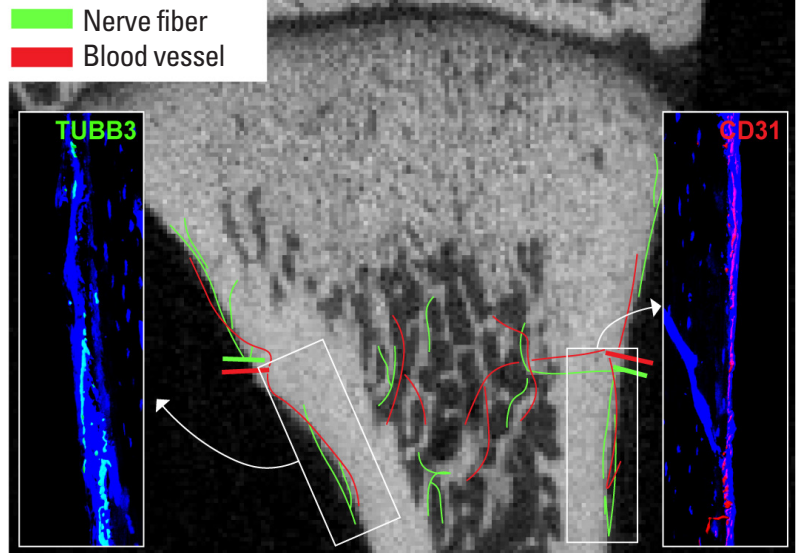

Fig. 1. Schematic representation of skeletal nerve fibers and their close proximity to the skeletal blood vessels. Skeletal nerve fibers are distributed and innervated in the periosteum, and cortical bone, and in the marrow microenvironment adjacent to the trabecular surface. Representative confocal microscopy images of the $\beta$-tubulin 3 (TUBB3)-expressing skeletal nerve fibers (left) and CD31-expressing blood vessels (right) in the periosteum.

pathway has been documented as the underlying mechanism regulating bone development,[15] fracture and defect healing, $[16,17]$ and heterotopic bone formation in soft tissue.[18] Since NGFs are more universal growth factors that attract and guide various types of nerve fibers in a flexible manner,[19] they regulate the sensory nerve fiber density and recruitment in conjunction with TrkA in the skeleton.

In addition to sensory nerve fibers, autonomic nerve fibers including sympathetic and parasympathetic nerve fibers are also found within the skeleton. The neurotransmitters associated with these nerve fibers extend their effects to osteoblasts and osteoclasts, demonstrating the participation of the autonomic nervous system in the neural modulation for bone remodeling and metabolism. Recent work has documented that the majority of sympathetic and parasympathetic nerves are located in close proximity to the blood vessels that highlight their typical relationship within the vascular structure.[20,21] Although there are a less prominent presence of tyrosine hydroxylase $(\mathrm{TH})^{+}$ fiber frequency seen in autonomic nerve fibers compared to calcitonin gene-related peptide (CGRP) ${ }^{+}$sensory nerve fibers,[16,18] sympathetic innervation in the skeleton suggests that there could be autonomic neural control of bone metabolism. Indeed, receptors for sympathetic nerves, including $a$ - and $\beta$-adrenergic receptors (AR), are expressed 
in the bone.[22-24] Immunohistochemical detection of $\mathrm{TH}^{+}$sympathetic fibers has been reported previously in the bone marrow area and nutrient foramina and is typically found wrapping around the bone vasculature.[13,14,20] More recent investigations have highlighted the presence of $\mathrm{TH}^{+}$nerves within the periosteum of long bones, calvarium, and in the peripheral tissue where ectopic bone formation is found.[16-18] Furthermore, parasympathetic nerve receptors, muscarinic acetylcholine receptor (mA$\mathrm{ChR}$ ) and nicotinic $\mathrm{AChR}$, are also found in bone cells, and the parasympathetic markers vesicular acetylcholine transporter and choline acetyltransferase target these receptors in osteoclasts to regulate bone resorption, although, direct measurement of parasympathetic innervation to the skeleton is deficient.[20,25,26]

\section{Functional roles of nerves in bone}

Transmission of nociceptive stimulations is the most common function of sensory nerves, which is extremely obvious in osteoarthritis, bone fracture or defect, and bone cancer. Studies of skeletal pain have primarily focused on NGF since it is a predominant conciliator of bone pain by conveying the pain sensation via TrkA-expressing sensory neurons or via other nociceptive pathways including transient receptor potential ion channels and nociceptive mechanotransducers. $[27,28]$ In addition to the nociceptor potentials of sensory nerves, a large body of literature has demonstrated the role of sensory nerves as a player in regulating osteoanabolic potentials. Sensory nerves that transmit pain sensation have been found to innervate the bone tissue and promote bone regeneration.[29-34] NGF stimulates the proliferation of sensory nerve fibers and increases sensory axonal growth, NGF treatment has been performed as an osteoanabolic mediator.[32,34] Sensory nerve denervation by high-affinity NGF receptor TrkA ablation also reduces skeletal nerve density and osteoblast-mediated bone formation, and further decreases bone volume in mice femora.[30] Similarly, Fukuda and colleagues demonstrated that specific manipulation of sensory nerves by deleting an axon guiding molecule semaphorin $3 \mathrm{~A}\left(\mathrm{Sema}^{\mathrm{a}}{ }^{-1}\right.$ ) in bone tissue, which is a molecule involved in nerve fiber ingrowth, impaired bone mass accrual, and resulted in osteoporosis-like conditions without affecting bone cells.[31] Moreover Sema3a ${ }^{-/-}$knockout animals had approximately a $40 \%$ reduction in bone regeneration capacity compared to control animals, which coincided with a $75 \%$ to $80 \%$ reduction in the sensory nerve innervation into the bone defect area.[31] In clinical cases, human patients with loss or failure of sensory nerve function had an increased incidence of bone fracture and reduced bone regeneration following injury. $[29,33]$ Thus, these findings strengthened the concept that bone metabolism and regeneration are closely linked to bone sensory nerve innervation and that a disruption in sensory innervation in the bone is associated with decreases in metabolism and regeneration.

Bone sympathetic nerves are also closely linked to bone metabolism; however, they have a catabolic effect on bone, traditionally through the hypothalamus-mediated serotonin and cyclic adenosine monophosphate-response element binding protein. $[35,36]$ Negative alterations in this signaling pathway will ultimately influence the sympathetic tone and stimulation to the skeleton. Increased sympathetic activity is known to stimulate osteoclastogenesis and osteoclast activity through ARs, and in turn help to regulate bone resorption.[37-39] Recently, an additional role of sensory stimulation on sympathetic nerves has been proposed, with studies sought to determine the effect of a sympathetic inhibitor, advillin-induced prostaglandin $E_{2}$ $\left(\mathrm{PGE}_{2}\right)$, on bone metabolism. Several reports demonstrated the bone anabolic effects of $\mathrm{PGE}_{2}$ by stimulating bone formation through PGE receptor 4 expressed in osteoblasts. $[30,40,41]$ In addition, increased sympathetic activity directly stimulates bone catabolic activity by augmenting osteoclastic bone resorption, whereas upregulation of $\mathrm{PGE}_{2}$ by advillin-expressing sensory nerves suppresses sympathetic nerve activity, therefore promoting osteoblasts proliferation and differentiation, and further increasing bone formation.[30] Perturbations of the autonomic system in a clinical setting can induce complex regional pain syndrome (CRPS) type I and II. In CRPS a skeletal (type I) or nerve (type II) injury produces intense pain coupled with local oedema, vasomotor dysfunction and sudomotor abnormalities in the affected areas.[42] A peripheral sympathetic blockade is an effective therapy for CPRS and is an option to consider in association with antiresorptive agents.[43]

In summary, sensory nerve fibers are inherently linked to bone remodeling and metabolism, and it is plausible that this link is mediated by NGF and TrkA pathways. Furthermore, the autonomic nervous system in the skeleton is also involved in bone metabolism and remodeling, although to 
a lesser extent and in an indirect fashion, and more thorough investigations are warranted to further elucidate this relationship.

\section{NERVES AND BONE DURING MODELS OF EXERCISE}

\section{Modulation of nerves and bone following exercise training}

In the previous section, the role played by skeletal nerves in bone development, bone fracture or defect healing, and bone remodeling were comprehensively discussed. Although aerobic exercise has been shown to play a positive role in both bone metabolism and the peripheral nervous system independently, the examination of exercise-induced associations between skeletal nerves and bone metabolism is limited. In this section of the review, an effective synthesis of the limited recent studies supporting the link between chronic exercise training and skeletal innervation and nerve density in bone, and the beneficial effect this has on bone anabolic activity will be provided. To date, there are only 3 studies directly testing the effect of exercise training on the skeletal nervous system and bone tissue-associated outcomes (Table 1). One study showed that increased sympathetic nerve stimulation by $\beta$-AR agonist treatment (salbutamol $[S A B]$ ) in ovariectomized (OVX) rats offset the positive effects of treadmill exercise training on bone, such that $S A B$ treatment caused lower bone volume, trabecular thickness, mineral apposition rate, long bone ultimate force, and stiffness in $\mathrm{OVX}+\mathrm{SAB}+$ exercise rats compared to $\mathrm{OVX}+$ exercise rats.[44] In contrast, a recent study used an aerobic exercise training model in middle-aged C57BL/6 mice to test the positive influence of prolonged exercise on the bone-associated skeletal nerves and bone metabolism.[10] They showed that 8 weeks of high-intensity treadmill exercise shows higher periosteal nerve fiber density by $99 \%$ and $88 \%$ in the distal femur and proximal tibia, respectively, which coincided with an increased bone area, bone mineral density, bone mineral content, and trabecular number.[10] Furthermore, the regeneration of propriospinal neurons was improved up to $70 \%$ following 4 weeks of cycling exercise and was associated with an increased mRNA expression of growth-associated protein 43 (GAP43), $\beta$-actin, and Neuritin, all of which play a role in nerve regeneration.[45] These findings are positive and highlight the potential of similar downstream effects of exercise training on bone nerves, however, these speculations require future confirmation.

Although there are no studies on the relationship between sensory nerve changes and bones during exercise training or physical activity, many studies have reported that various exercise, such as swimming,[46] voluntary wheel running,[47] and forced treadmill running,[48] accelerated sensory nerve regeneration and improves nerve function in the periphery. Judging from the significant effects of sensory nerves on bone metabolism and bone formation, it is possible to speculate that improvement of sensory nerve function and increased sensory nerve regeneration through exercise training will affect bone metabolism and anabolic activity. While the number of studies directly testing the effects of chronic exercise training on bone nerves is limited, there are others that use a mechanical loading model to mimic the effects of exercise, which will be discussed in the next section.

\section{Modulation of nerves and bone following mechanical loading}

Mechanical loading of the skeletal system has long been

Table 1. Summary of studies investigating the relationship between exercise models and altered bone and nerve structure and function

\begin{tabular}{|c|c|c|c|c|}
\hline References & Types of nerve & Exercise mode & Nerve & Effect on bone \\
\hline $\begin{array}{l}\text { Bonnet } \\
\text { et al.[44] }\end{array}$ & Autonomic nerves & $\begin{array}{l}\text { Treadmill exercise }(13 \mathrm{~m} / \mathrm{min} \text {, } \\
10 \text { weeks) }\end{array}$ & $\begin{array}{l}\text { SAB-induced } \uparrow \text { sympathetic stimulation in } \\
\text { OVX rats }\end{array}$ & $\begin{array}{l}\text { SAB } \downarrow \text { benefits of exercise: } \downarrow \text { MAR, } \\
\text { BV/TV, Tb.Th, ultimate force, stiff- } \\
\text { ness }\end{array}$ \\
\hline Lee et al.[10] & Not characterized & $\begin{array}{l}\text { Treadmill exercise }(18 \mathrm{~m} / \mathrm{min} \text {, } \\
8 \text { weeks) }\end{array}$ & $\begin{array}{l}\beta \text {-tubulin } 3^{+} \text {nerve } \uparrow \text { in distal femoral and } \\
\text { proximal tibial periosteum }\end{array}$ & $\begin{array}{l}\uparrow \text { bone area, BMD, BMC of femur } \\
\text { and tibia, } \uparrow \text { Tb.N of tibia }\end{array}$ \\
\hline $\begin{array}{l}\text { Sachdeva } \\
\text { et al.[45] }\end{array}$ & $\begin{array}{l}\text { Central and sensory } \\
\text { nerves }\end{array}$ & $\begin{array}{l}\text { Cycling exercise ( } 45 \mathrm{rpm} \text { for } \\
30 \mathrm{~min} / \text { day, } 4 \text { weeks) }\end{array}$ & $\begin{array}{l}\uparrow \text { propriospinal neurons number, length/no } \\
\text { change in peripheral sensory nerves }\end{array}$ & No direct measurement \\
\hline
\end{tabular}

SAB, salbutamol; OVX, ovariectomized; MAR, mineral apposition rate; BV/TV, bone volume to total volume ratio; Tb.N, trabecular number; Tb.Th, trabecular thickness; BMD, bone mineral density; BMC, bone mineral content. 
Table 2. Summary of studies investigating the relationship between mechanical loading models and altered bone and nerve structure and function

\begin{tabular}{|c|c|c|c|c|}
\hline References & Types of nerve & Mechanical loading & Nerve & Effect on bone \\
\hline $\begin{array}{l}\text { Tomlinson } \\
\text { et al.[49] }\end{array}$ & Sensory nerves & Axial ulna compression & $\begin{array}{l}\text { TrkA inhibition with 1NMPP1 } \\
\downarrow \text { sensory nerve sprouting, } \\
\text { NGF treatment } \uparrow \text { sensory function }\end{array}$ & $\begin{array}{l}\downarrow \text { bone formation rate, } \downarrow \text { Wnt } / \beta \text {-Catenin } \\
\text { activity, } \uparrow \text { bone formation rate, } \uparrow \text { Wnt/ } \\
\beta \text {-Catenin activity }\end{array}$ \\
\hline $\begin{array}{l}\text { Fioravanti } \\
\text { et al.[50] }\end{array}$ & Sensory nerves & Axial ulna compression & $\begin{array}{l}\text { TrkA agonist gambogic amide } \\
\uparrow \text { sensory function (no direct nerve } \\
\text { measurement), } \uparrow \text { Ngf gene expression }\end{array}$ & $\begin{array}{l}\uparrow \text { bone formation rate, } \uparrow \text { osteoblast recruit- } \\
\text { ment, } \uparrow \text { osteoblast differentiation }\end{array}$ \\
\hline Heffner et al.[51] & Sensory nerves & Axial tibial compression & $\begin{array}{l}\text { Capsaicin } \downarrow \text { sensory nerve function, } \\
\quad \downarrow \text { thermal sensitivity }\end{array}$ & $\downarrow$ BV/TV, Tb.Th \\
\hline Sample et al.[52] & Sensory nerves & Axial ulna compression & $\begin{array}{l}\text { Brachial plexus anesthesia } \downarrow \text { sensory nerve } \\
\text { function }\end{array}$ & $\downarrow$ labeled bone area \\
\hline Jiao et al.[78] & $\begin{array}{l}\text { Autonomic } \\
\text { nerves }\end{array}$ & Biomechanical loading & Chemical sympathectomy $\downarrow$ norepinephrine & $\begin{array}{l}\uparrow \mathrm{BMD}, \mathrm{BV} / \mathrm{TV} \text {, Tb.Th, } \uparrow \text { bone formation } \\
\text { rate }\end{array}$ \\
\hline
\end{tabular}

TrkA, tropomyosin receptor kinase A; 1NMPP1, cell-permeable PP1 analog; NGF, nerve growth factor; BV/TV, bone volume to total volume ratio; Tb.Th, trabecular thickness; BMD, bone mineral density.

used as an experimental model to mimic the effects of exercise in rodents. Recent studies adopting this model have begun to explore the effects of mechanical loading on skeletal innervation (Table 2). Tomlinson et al. [49] found that load-induced (axial compression) bone formation was inhibited in mice with TrkA deletion (via small molecule 1NMPP1), which was restored following NGF treatment via upregulation of the Wnt- $\beta$ catenin signaling pathway. Interestingly, a recent study has shown that mice administered with a TrkA agonist, gambogic amide (GA), had increased bone formation following mechanical-loading due to an augmentation in osteoblast recruitment and differentiation.[50] Even though the authors did not test the sensory innervation to bone tissue and did not see the changes in hyperalgesia following GA treatment, it seems conceivable that an upregulation of $\mathrm{Ngf}$ and $\mathrm{Wnt7b}$ gene expression during ulna axial loading with $G A$ will show the TrkA agonizing effects of GA.[50] Furthermore, in another study, sensory degeneration by capsaicin treatment resulted in a decrease in trabecular bone microarchitecture during normal loading conditions.[51] Therefore, it seems that functional bone adaptation to the mechanical loading is neuronally regulated, mainly by sensory nerves, and that the sensory neural signals are associated with increased bone formation, possibly via increasing osteoblast activity. [52]

Although skeletal adaptation during mechanical loading is different to exercise training or physical activity, these are established models to mimic exercise in animals. The number of studies testing the exercise effects are limited to date, and thus the conclusions of this review must be tempered. However, as mentioned in the previous sections, enhanced skeletal innervation and nerve signaling stimulate bone development, fracture, and defect repair. Moreover, disrupted skeletal nerve signaling due to peripheral neuropathy, negatively effects bone adaptation. Therefore, one can begin to appreciate the consolidative nature of the skeletal nerve signaling and the skeletal system, and that exercise training may provide sufficient stimulation for skeletal nervous system to lead to bone anabolism.

\section{FUTURE RESEARCH DIRECTIONS IN EXERCISE AND SKELETAL NERVES}

Epidemiological observations suggested that in response to physical activity and exercise training, cognitive function is improved and provides some form of protection against the development of neurological disorders, such as dementia, brain aging $[6,7]$ and Parkinson's disease.[8,9] Exercise training models in rodents have shown that axon regeneration of the median nerve was promoted by treadmill exercise training,[53-55] and improved nerve regeneration is a result of a concomitant upregulation of neurotrophic factors, such as glial derived neurotrophic factor (GDNF), brain derived neurotrophic factor (BDNF), and insulin-like growth factor-1.[54] Similarly, wheel and treadmill running has also been shown to prevent rodents from developing chemotherapy-induced and diabetic peripheral neuropathy, such that peripheral nerve innervation and density were maintained by exercise training. $[56,57]$ Based on the aforementioned data in peripheral nerves, it is possible that similar changes could be seen in the skeletal ner- 
vous system in response to chronic exercise training. However, the extent to which exercise-induced increases in bone innervation contribute to improvements in skeletal remodeling and metabolism remains an intriguing unanswered question.

From the current review's perspective, the potential relationship between bone nerves and neurotrophins expressed in osteochondral cells (Fig. 2), known to be released following exercise training and physical activity,[58-63] is an important and exciting avenue for future research. These neurotrophins may mediate neuro-skeletal interactions and stimulate skeletal nerve fibers responsible for positively regulating osteogenesis. Thus, exercise-induced changes in neurotrophins may play a significant role in skeletal nerve ingrowth, mediate innervation, and/or maintain skeletal nerve integrity.[26] Results from rodent models suggest that exercise-derived neurotrophic factors including NGF,[58] BDNF,[47,54,59-61] neurotrophin-3,[47,59,61] neurotroph-

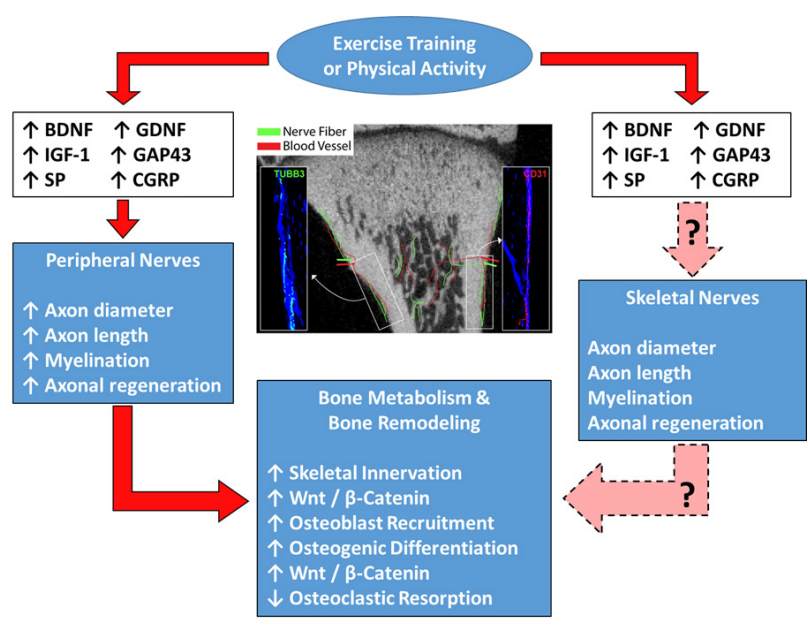

Fig. 2. The relationship between exercise training, peripheral (skeletal) nerves, and bone health. A flow diagram illustrating the mechanistic pathways upregulated and downregulated in response to exercise training and their effects on peripheral and skeletal nerves, and the potential effect this could have on bone innervation and metabolism. Altogether, this provides many potential possibilities for exercise-mediated regulation of skeletal nervous system, and further bone metabolism and homeostasis. The extent to which exercise-induced increases in bone innervation contributes to improvements in skeletal cell metabolism remains an intriguing unanswered question. BDNF, brain derived neurotrophic factor; GDNF, glial derived neurotrophic factor; IGF-1, insulin-like growth factor-1; GAP43, growth-associated protein 43; SP, substance P; CGRP, calcitonin gene-related peptide. in-4,[59,61] and GDNF [54] can promote peripheral nerve outgrowth and ingrowth. Moreover, synaptic vesicle protein (Synapsin I) has been linked to neurite growth and stimulates neurotransmitter release.[47] GAP43 has also been shown to be responsible for axonal growth and improvement of synaptic function. $[45,47]$ Both Synapsin I and CAP43 expressions are elevated following exercise training, and triggered neurogenesis.[47,58] Sensory nerve mediated osteotropic actions can be induced by nerve fiber-releasing neuropeptides, such as CGRP, substance $P$ (SP), and Galanin.[63] These neurotransmitters are secreted from sensory nerve terminals abundant in bone tissue and are thought to transmit physiological signals to bone remodeling cells, such as osteoclasts and osteoblasts, to promote bone anabolic activity and bone metabolism.[26,39] The classical sensory neuropeptides CGRP, SP, and Galanin are found in skeletal sensory nerves and following exercise training have been shown to directly affect osteoblasts, $[40,46]$ increase mRNA expression of SP, [62] and augment serum concentration of CGRP [64] and Galanin.[65] Specifically, since CGRP has been demonstrated to increase Wnt signaling-mediated osteoblast activity [66] and prevent osteoblast and osteocytes apoptosis,[66,67] Wht signaling activity associated with the mechanical load-induced sensory nerves activation and osteoblast recruitment $[49,50]$ reveals its regulator potential for bone formation. Nevertheless, the physiological alterations of NGF-TrkA-expressing sensory nerves following exercise training and physical activity are lacking and are the potential subject for detailed future investigation.

Greater knowledge and understanding of the mechanistic link between chronic exercise training and bone innervation are required, however, the potential clinical impact this work could have in developing new therapies is outstanding. Indeed, several clinical entities in bone pathology have been demonstrated to be related to nerve dysfunction. For example, diabetic neuropathy is a common peripheral neuropathy with crippling clinical consequences. It is well-known that diabetic neuropathy is associated with delayed bone fracture repair,[68-70] and diabetic neuropathy is an independent risk factor for delayed or failure of fracture repair.[71] In addition, chemotherapy-induced peripheral neuropathy (CIPN) is one of the most common complications seen in cancer patients who are treated with chemotherapy drugs since the sensory nerves in the distal 
side of the body are exceptionally susceptible to microtubules stabilization, with one study highlighting that over $80 \%$ of total cancer patients experienced this complication.[72] Interestingly, similar findings have been seen in mice treated with chemotherapy, whereby reduced peripheral nerve fiber density phenocopies were found in the bone tissue resulting in a decreased nerve reorganization and delayed fracture repair.[16] Likewise, another recent study in dogs reported that the chemotherapeutic agent Cisplatin also prevented osteogenic processes and bone growth during distraction osteogenesis.[73,74] Therefore, there is growing evidence to suggest that CIPN compromises bone integrity and metabolism in human patients and animals, highlighting a need for counter-therapies such as exercise training to offset the negative effects of chemotherapy.

Charcot arthropathy is another clinical condition that induces a severe degeneration of bone and joints. This clinical entity is common in diabetes, and peripheral or central neuropathies including leprosy, polio, chronic alcoholism, or syringomyelia.[75] In these cases, a change in sympathetic tone results in increased blood flow, osteoclastogenesis, osteopenia, fracture and acute inflammation.[76] In addition, a case report recently revealed that people with hereditary neuropathy that involved the sensory or motor nerve system, such as Charcot-Marie-Tooth disease, showed an increased fracture incidence risk, decreased bone mass, and severe deterioration of the proximal tibial trabecular bone microarchitecture.[77] These appearances of clinical confirmation in human patients again highlight the potential therapeutic role of chronic exercise training to offset these negative effects and provide meaningful clinical improvements in skeletal innervation and bone metabolism. Nevertheless, more precise and detailed in vivo and in vitro examinations are required to support the role of exercise on the skeletal nervous system, which could have a profound impact on the clinical translation of exercise training as a therapy in a wide variety of clinical conditions in which impairments in bone metabolism and bone innervation are implicated.

\section{CONCLUSION}

Recent studies utilizing exercise training or mechanical loading models suggest that the mechanical load associat- ed with exercise results in beneficial improvements in skeletal innervation. The influence of exercise training models on the relationship between sensory nerve signals and osteoblast-mediated bone formation and increased bone volume provides the first insight into the potential importance of exercise training in stimulating positive adaptations in the skeletal nerve-bone interaction and its downstream effect on bone metabolism, thus highlighting its therapeutic potential in a variety of clinical populations.

\section{DECLARATIONS}

\section{Acknowledgments}

We would like to sincerely thank the officials of the Korean Society for Bone and Mineral Research (KSBMR) for inviting us to submit this review paper consideration for publication to the Journal of Bone Metabolism.

\section{Authors' contributions}

All authors contributed to the development of this review article. SL conceived the idea for the manuscript. SN and SL searched and reviewed relevant literature. SN, TJS, and SL wrote the original draft, and SN, TJS, and SL reviewed and edited the manuscript. All authors read and approved the final manuscript.

\section{Ethics approval and consent to participate Not applicable.}

\section{Conflict of interest}

No potential conflict of interest relevant to this article was reported.

\section{ORCID}

Stefano Negri https://orcid.org/0000-0003-2218-6654

T. Jake Samuel https://orcid.org/0000-0001-7638-1864

Seungyong Lee https://orcid.org/0000-0002-5397-6889

\section{REFERENCES}

1. Frost HM. The skeletal intermediary organization. Metab Bone Dis Relat Res 1983;4:281-90. https://doi.org/10.1016/ s0221-8747(83)80001-0.

2. Hauge EM, Qvesel D, Eriksen EF, et al. Cancellous bone remodeling occurs in specialized compartments lined by 
cells expressing osteoblastic markers. J Bone Miner Res 2001;16:1575-82. https://doi.org/10.1359/jbmr.2001.16.9. 1575.

3. Yokota H, Leong DJ, Sun HB. Mechanical loading: Bone remodeling and cartilage maintenance. Curr Osteoporos Rep 2011;9:237-42. https://doi.org/10.1007/s11914-0110067-y.

4. Thompson WR, Rubin CT, Rubin J. Mechanical regulation of signaling pathways in bone. Gene 2012;503:179-93. https://doi.org/10.1016/j.gene.2012.04.076.

5. Rubin J, Rubin C, Jacobs CR. Molecular pathways mediating mechanical signaling in bone. Gene 2006;367:1-16. https://doi.org/10.1016/j.gene.2005.10.028.

6. Erickson KI, Weinstein AM, Lopez OL. Physical activity, brain plasticity, and Alzheimer's disease. Arch Med Res 2012;43: 615-21. https://doi.org/10.1016/j.arcmed.2012.09.008.

7. Hötting K, Röder B. Beneficial effects of physical exercise on neuroplasticity and cognition. Neurosci Biobehav Rev 2013;37:2243-57. https://doi.org/10.1016/j.neubiorev.2013. 04.005.

8. Burini D, Farabollini B, lacucci S, et al. A randomised controlled cross-over trial of aerobic training versus Qigong in advanced Parkinson's disease. Eura Medicophys 2006;42: 231-8.

9. Miyai I, Fujimoto Y, Ueda Y, et al. Treadmill training with body weight support: its effect on Parkinson's disease. Arch Phys Med Rehabil 2000;81:849-52. https://doi.org/ 10.1053/apmr.2000.4439.

10. Lee S, Shin YA, Cho J, et al. Augmented skeletal nerves are associated with high-intensity aerobic exercise-induced bone gain in middle-aged mice. ASBMR 2021 Annual Meeting; 2021 Oct 1-4; Austin, TX: American Society for Bone and Mineral Research.

11. Chenu C. Role of innervation in the control of bone remodeling. J Musculoskelet Neuronal Interact 2004;4:132-4.

12. Hara-Irie F, Amizuka N, Ozawa H. Immunohistochemical and ultrastructural localization of CGRP-positive nerve fibers at the epiphyseal trabecules facing the growth plate of rat femurs. Bone 1996;18:29-39. https://doi.org/10.1016/ 8756-3282(95)00425-4.

13. Mach DB, Rogers SD, Sabino MC, et al. Origins of skeletal pain: sensory and sympathetic innervation of the mouse femur. Neuroscience 2002;113:155-66. https://doi.org/10. 1016/s0306-4522(02)00165-3.

14. Castañeda-Corral G, Jimenez-Andrade JM, Bloom AP, et al.
The majority of myelinated and unmyelinated sensory nerve fibers that innervate bone express the tropomyosin receptor kinase A. Neuroscience 2011;178:196-207. https: //doi.org/10.1016/j.neuroscience.2011.01.039.

15. Tomlinson RE, Li Z, Zhang Q, et al. NGF-TrkA signaling by sensory nerves coordinates the vascularization and ossification of developing endochondral bone. Cell Rep 2016; 16:2723-35. https://doi.org/10.1016/j.celrep.2016.08.002.

16. Li Z, Meyers CA, Chang L, et al. Fracture repair requires TrkA signaling by skeletal sensory nerves. J Clin Invest 2019;129: 5137-50. https://doi.org/10.1172/jci128428.

17. Meyers CA, Lee S, Sono T, et al. A neurotrophic mechanism directs sensory nerve transit in cranial bone. Cell Rep 2020; 31:107696. https://doi.org/10.1016/j.celrep.2020.107696.

18. Lee S, Hwang C, Marini S, et al. NGF-TrkA signaling dictates neural ingrowth and aberrant osteochondral differentiation after soft tissue trauma. Nat Commun 2021;12:4939. https://doi.org/10.1038/s41467-021-25143-z.

19. Kolodkin AL, Tessier-Lavigne M. Mechanisms and molecules of neuronal wiring: a primer. Cold Spring Harb Perspect Biol 2011;3:a001727. https://doi.org/10.1101/cshperspect.a001727.

20. Brazill JM, Beeve AT, Craft CS, et al. Nerves in bone: Evolving concepts in pain and anabolism. J Bone Miner Res 2019; 34:1393-406. https://doi.org/10.1002/jbmr.3822.

21. Tabarowski Z, Gibson-Berry K, Felten SY. Noradrenergic and peptidergic innervation of the mouse femur bone marrow. Acta Histochem 1996;98:453-7. https://doi.org/ 10.1016/s0065-1281(96)80013-4.

22. Hamajima K, Hamamura K, Chen A, et al. Suppression of osteoclastogenesis via a2-adrenergic receptors. Biomed Rep 2018;8:407-16. https://doi.org/10.3892/br.2018.1075.

23. Khosla S, Drake MT, Volkman TL, et al. Sympathetic $\beta 1$-adrenergic signaling contributes to regulation of human bone metabolism. J Clin Invest 2018;128:4832-42. https://doi. org/10.1172/jci122151.

24. Ma Y, Nyman JS, Tao $\mathrm{H}$, et al. $\beta 2$-Adrenergic receptor signaling in osteoblasts contributes to the catabolic effect of glucocorticoids on bone. Endocrinology 2011;152:141222. https://doi.org/10.1210/en.2010-0881.

25. Bajayo A, Bar A, Denes A, et al. Skeletal parasympathetic innervation communicates central IL-1 signals regulating bone mass accrual. Proc Natl Acad Sci U S A 2012;109:1545560. https://doi.org/10.1073/pnas.1206061109.

26. Tomlinson RE, Christiansen BA, Giannone AA, et al. The 
role of nerves in skeletal development, adaptation, and aging. Front Endocrinol (Lausanne) 2020;11:646. https:// doi.org/10.3389/fendo.2020.00646.

27. Mendell LM, Albers KM, Davis BM. Neurotrophins, nociceptors, and pain. Microsc Res Tech 1999;45:252-61. https: //doi.org/10.1002/(sici)1097-0029(19990515/01)45:4/5< 252::Aid-jemt9>3.0.Co;2-n.

28. Zhang X, Huang J, McNaughton PA. NGF rapidly increases membrane expression of TRPV1 heat-gated ion channels. EMBO J 2005;24:4211-23. https://doi.org/10.1038/sj.emboj.7600893.

29. Bar-On E, Weigl D, Parvari R, et al. Congenital insensitivity to pain. Orthopaedic manifestations. J Bone Joint Surg Br 2002;84:252-7. https://doi.org/10.1302/0301-620x.84b2.11939.

30. Chen H, Hu B, Lv X, et al. Prostaglandin E2 mediates sensory nerve regulation of bone homeostasis. Nat Commun 2019;10:181. https://doi.org/10.1038/s41467-018-08097-7.

31. Fukuda T, Takeda $S, X u$ R, et al. Sema3A regulates bonemass accrual through sensory innervations. Nature 2013; 497:490-3. https://doi.org/10.1038/nature12115.

32. Grills BL, Schuijers JA, Ward AR. Topical application of nerve growth factor improves fracture healing in rats. J Orthop Res 1997;15:235-42. https://doi.org/10.1002/jor.1100150212.

33. Pérez-López LM, Cabrera-González M, Gutiérrez-de la Iglesia $D$, et al. Update review and clinical presentation in congenital insensitivity to pain and anhidrosis. Case Rep Pediatr 2015;2015:589852. https://doi.org/10.1155/2015/589852.

34. Wang L, Zhou S, Liu B, et al. Locally applied nerve growth factor enhances bone consolidation in a rabbit model of mandibular distraction osteogenesis. J Orthop Res 2006; 24:2238-45. https://doi.org/10.1002/jor.20269.

35. Ortuño MJ, Robinson ST, Subramanyam P, et al. Serotoninreuptake inhibitors act centrally to cause bone loss in mice by counteracting a local anti-resorptive effect. Nat Med 2016;22:1170-9. https://doi.org/10.1038/nm.4166.

36. Oury F, Yadav VK, Wang Y, et al. CREB mediates brain serotonin regulation of bone mass through its expression in ventromedial hypothalamic neurons. Genes Dev 2010;24: 2330-42. https://doi.org/10.1101/gad.1977210.

37. Even-Ram S, Artym V, Yamada KM. Matrix control of stem cell fate. Cell 2006;126:645-7. https://doi.org/10.1016/ j.cell.2006.08.008.

38. Kondo $\mathrm{H}$, Togari A. Continuous treatment with a low-dose $\beta$-agonist reduces bone mass by increasing bone resorption without suppressing bone formation. Calcif Tissue Int
2011;88:23-32. https://doi.org/10.1007/s00223-010-9421-9.

39. Qiao Y, Wang Y, Zhou Y, et al. The role of nervous system in adaptive response of bone to mechanical loading. J Cell Physiol 2019;234:7771-80. https://doi.org/10.1002/jcp.27683.

40. Minamizaki T, Yoshiko Y, Kozai K, et al. EP2 and EP4 receptors differentially mediate MAPK pathways underlying anabolic actions of prostaglandin E2 on bone formation in rat calvaria cell cultures. Bone 2009;44:1177-85. https:// doi.org/10.1016/j.bone.2009.02.010.

41. Raisz LG, Woodiel FN. Effects of selective prostaglandin EP2 and EP4 receptor agonists on bone resorption and formation in fetal rat organ cultures. Prostaglandins Other Lipid Mediat 2003;71:287-92. https://doi.org/10.1016/ s1098-8823(03)00049-2.

42. Bruehl S. Complex regional pain syndrome. BMJ 2015;351: h2730. https://doi.org/10.1136/bmj.h2730.

43. Duong S, Bravo D, Todd KJ, et al. Treatment of complex regional pain syndrome: an updated systematic review and narrative synthesis. Can J Anaesth 2018;65:658-84. https: //doi.org/10.1007/s12630-018-1091-5.

44. Bonnet $\mathrm{N}$, Laroche $\mathrm{N}$, Beaupied $\mathrm{H}$, et al. Doping dose of salbutamol and exercise training: impact on the skeleton of ovariectomized rats. J Appl Physiol (1985) 2007;103: 524-33. https://doi.org/10.1152/japplphysiol.01319.2006.

45. Sachdeva R, Theisen CC, Ninan V, et al. Exercise dependent increase in axon regeneration into peripheral nerve grafts by propriospinal but not sensory neurons after spinal cord injury is associated with modulation of regeneration-associated genes. Exp Neurol 2016;276:72-82. https://doi. org/10.1016/j.expneurol.2015.09.004.

46. Teodori RM, Betini J, de Oliveira LS, et al. Swimming exercise in the acute or late phase after sciatic nerve crush accelerates nerve regeneration. Neural Plast 2011;2011:783901. https://doi.org/10.1155/2011/783901.

47. Molteni R, Zheng JQ, Ying Z, et al. Voluntary exercise increases axonal regeneration from sensory neurons. Proc Natl Acad Sci U S A 2004;101:8473-8. https://doi.org/10. 1073/pnas.0401443101.

48. Goulart $C O$, Jürgensen $S$, Souto $A$, et al. A combination of Schwann-cell grafts and aerobic exercise enhances sciatic nerve regeneration. PLoS One 2014;9:e110090. https:// doi.org/10.1371/journal.pone.0110090.

49. Tomlinson RE, Li Z, Li Z, et al. NGF-TrkA signaling in sensory nerves is required for skeletal adaptation to mechanical loads in mice. Proc Natl Acad Sci U S A 2017;114:E3632-41. 
https://doi.org/10.1073/pnas.1701054114.

50. Fioravanti G, Hua PQ, Tomlinson RE. The TrkA agonist gambogic amide augments skeletal adaptation to mechanical loading. Bone 2021;147:115908. https://doi.org/10.1016/ j.bone.2021.115908.

51. Heffner MA, Anderson MJ, Yeh GC, et al. Altered bone development in a mouse model of peripheral sensory nerve inactivation. J Musculoskelet Neuronal Interact 2014;14:1-9.

52. Sample SJ, Behan M, Smith L, et al. Functional adaptation to loading of a single bone is neuronally regulated and involves multiple bones. J Bone Miner Res 2008;23:1372-81. https://doi.org/10.1359/jbmr.080407.

53. English AW, Cucoranu D, Mulligan A, et al. Treadmill training enhances axon regeneration in injured mouse peripheral nerves without increased loss of topographic specificity. J Comp Neurol 2009;517:245-55. https://doi.org/10. 1002/cne.22149.

54. Park JS, Höke A. Treadmill exercise induced functional recovery after peripheral nerve repair is associated with increased levels of neurotrophic factors. PLoS One 2014;9: e90245. https://doi.org/10.1371/journal.pone.0090245.

55. Sabatier MJ, Redmon N, Schwartz G, et al. Treadmill training promotes axon regeneration in injured peripheral nerves. Exp Neurol 2008;211:489-93. https://doi.org/10.1016/j. expneurol.2008.02.013.

56. Groover AL, Ryals JM, Guilford BL, et al. Exercise-mediated improvements in painful neuropathy associated with prediabetes in mice. Pain 2013;154:2658-67. https://doi.org/ 10.1016/j.pain.2013.07.052.

57. Park JS, Kim S, Hoke A. An exercise regimen prevents development paclitaxel induced peripheral neuropathy in a mouse model. J Peripher Nerv Syst 2015;20:7-14. https:// doi.org/10.1111/jns.12109.

58. Chae $\mathrm{CH}$, Jung $\mathrm{SL}$, An SH, et al. Swimming exercise stimulates neuro-genesis in the subventricular zone via increase in synapsin I and nerve growth factor levels. Biol Sport 2014;31:309-14. https://doi.org/10.5604/20831862.1132130.

59. Côté MP, Azzam GA, Lemay MA, et al. Activity-dependent increase in neurotrophic factors is associated with an enhanced modulation of spinal reflexes after spinal cord injury. J Neurotrauma 2011;28:299-309. https://doi.org/ 10.1089/neu.2010.1594.

60. Hutchinson KJ, Gómez-Pinilla F, Crowe MJ, et al. Three exercise paradigms differentially improve sensory recovery after spinal cord contusion in rats. Brain 2004;127:1403-
14. https://doi.org/10.1093/brain/awh160.

61. Keeler BE, Liu G, Siegfried RN, et al. Acute and prolonged hindlimb exercise elicits different gene expression in motoneurons than sensory neurons after spinal cord injury. Brain Res 2012;1438:8-21. https://doi.org/10.1016/j.brainres. 2011.12.015.

62. Lind H, Brudin L, Lindholm L, et al. Different levels of sensory neuropeptides (calcitonin gene-related peptide and substance P) during and after exercise in man. Clin Physiol 1996;16:73-82. https://doi.org/10.1111/j.1475-097x.1996. tb00557.x.

63. Pongratz $G$, Straub RH. Role of peripheral nerve fibres in acute and chronic inflammation in arthritis. Nat Rev Rheumatol 2013;9:117-26. https://doi.org/10.1038/nrrheum. 2012.181.

64. Tarperi C, Sanchis-Gomar F, Montagnana M, et al. Effects of endurance exercise on serum concentration of calcitonin gene-related peptide (CGRP): a potential link between exercise intensity and headache. Clin Chem Lab Med 2020; 58:1707-12. https://doi.org/10.1515/cclm-2019-1337.

65. Liang Y, Sheng $S$, Fang $P$, et al. Exercise-induced galanin release facilitated GLUT4 translocation in adipocytes of type 2 diabetic rats. Pharmacol Biochem Behav 2012;100: 554-9. https://doi.org/10.1016/j.pbb.2011.10.026.

66. Mrak E, Guidobono F, Moro G, et al. Calcitonin gene-related peptide (CGRP) inhibits apoptosis in human osteoblasts by $\beta$-catenin stabilization. J Cell Physiol 2010;225:701-8. https://doi.org/10.1002/jcp.22266.

67. Plotkin LI, Weinstein RS, Parfitt AM, et al. Prevention of osteocyte and osteoblast apoptosis by bisphosphonates and calcitonin. J Clin Invest 1999;104:1363-74. https://doi. org/10.1172/jci6800.

68. Forst T, Pfützner A, Kann P, et al. Peripheral osteopenia in adult patients with insulin-dependent diabetes mellitus. Diabet Med 1995;12:874-9. https://doi.org/10.1111/j.14645491.1995.tb00389.x.

69. Kanazawa I, Takeno A, Tanaka Kl, et al. Osteoporosis and vertebral fracture are associated with deterioration of activities of daily living and quality of life in patients with type 2 diabetes mellitus. J Bone Miner Metab 2019;37:503-11. https://doi.org/10.1007/s00774-018-0948-6.

70. Kim JH, Jung MH, Lee JM, et al. Diabetic peripheral neuropathy is highly associated with nontraumatic fractures in Korean patients with type 2 diabetes mellitus. Clin Endocrinol (Oxf) 2012;77:51-5. https://doi.org/10.1111/j.1365- 
2265.2011.04222.x.

71. Shibuya N, Humphers JM, Fluhman BL, et al. Factors associated with nonunion, delayed union, and malunion in foot and ankle surgery in diabetic patients. J Foot Ankle Surg 2013;52:207-11. https://doi.org/10.1053/j.jfas.2012. 11.012.

72. Höke A. Animal models of peripheral neuropathies. Neurotherapeutics 2012;9:262-9. https://doi.org/10.1007/s13311012-0116-y.

73. Stine KC, Wahl EC, Liu L, et al. Nutlin-3 treatment spares cisplatin-induced inhibition of bone healing while maintaining osteosarcoma toxicity. J Orthop Res 2016;34:171624. https://doi.org/10.1002/jor.23192.

74. Stine KC, Wahl EC, Liu L, et al. Cisplatin inhibits bone healing during distraction osteogenesis. J Orthop Res 2014; 32:464-70. https://doi.org/10.1002/jor.22527.
75. Embil JM, Trepman E. A case of diabetic Charcot arthropathy of the foot and ankle. Nat Rev Endocrinol 2009;5:57781. https://doi.org/10.1038/nrendo.2009.174.

76. Sono T, Meyers CA, Miller D, et al. Overlapping features of rapidly progressive osteoarthrosis and Charcot arthropathy. J Orthop 2019;16:260-4. https://doi.org/10.1016/j.jor. 2019.02.015.

77. Abdala R, Levi L, Longobardi V, et al. Severe bone microarchitecture deterioration in a family with hereditary neuropathy: evidence of the key role of the mechanostat. Osteoporos Int 2020;31:2477-80. https://doi.org/10.1007/ s00198-020-05674-9.

78. Jiao K, Niu L, Xu X, et al. Norepinephrine regulates condylar bone loss via comorbid factors. J Dent Res 2015;94:81320. https://doi.org/10.1177/0022034515577677. 
